root operations would have been carried out had it not been for the pressure on in-patient accommodation by tumour bearers. The figures in Table $I$ are selfexplanatory.

$$
\begin{aligned}
& \text { TABLE II.-Analysis of 1,000 Cases } \\
& \begin{array}{lllllllll}
\text { 1. Gliomas } & \text {. } & \text {. } & \text {.. } & \text {.. } & \text {.. } & \text {.. } & \text {. } & 365
\end{array}
\end{aligned}
$$

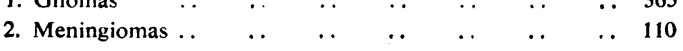

$$
\begin{aligned}
& \begin{array}{llllllll}
\text { 3. Pituitary adenomas } & . . & . & \text {.. } & \text {.. } & \text {. } & \text {.. } & 117
\end{array}
\end{aligned}
$$

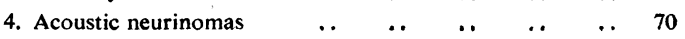

$$
\begin{aligned}
& \text { 5. Congenital cysts : } \\
& \text { Pituitary .. } \\
& \text { Third ventricle } \\
& \text { Meningeal .. } \\
& \text { Epidermoids }
\end{aligned}
$$

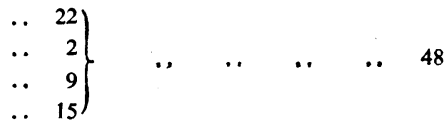

There were at the same time 58 primary tumours of the spinal cord, its roots, or membranes.

\section{Intracranial Lesions}

Space will not permit of detailed analysis of the foregoing list of the intracranial lesions which form the main body of the neurosurgeon's work. A certain number of gliomas have been omitted because the patients died immediately after admission or were in too bad condition to allow of surgery. One important thing must be said on this point: that a most careful evaluation must be made to decide whether a very ill patient is so because he has (a) an invasive destructive lesion, or (b) a benign one with general high pressure. It is only the latter group which are worth considering surgically. And it should be added that once a patient is known to have a tumour a waiting policy, for fear of possible operative fatality, is the surest way to bring about that result. A degree of high pressure may develop which will invalidate attempts at removal later. To make a comparison, it is generally held that the results of extirpation of carcinoma of the colon would be brilliant were it not for the high mortality introduced by obstruction. In neurosurgery the results would be even better were the pressure problem to be eliminated by very early diagnosis. Certainly the easiest cases are commonly the safest, and the greatest measure of safety can only lie in early intervention. Best of all, therefore, a benign tumour before pressure has introduced such technical difficulties into the picture that no proper exposure of the tumour, much less its removal, can be accomplished. We cannot, unfortunately, cause our patients to have the kind of tumour that we would wish to find, but we should be able to recognize its type and to use a wise discretion as to what to do and when, and to learn, above all, when to do nothing.

What mortality can be expected? This is a vexing question: mortality can be kept at a very low level by refusing to take risks. We may well sympathize with J. B. Murphy, who refused the condolences of his wife on some fatalities by saying that he ought to have been a good enough surgeon to know that the patient would die if he operated. Most of us know what Murphy felt, but we have equally to beware of timidity that may work to our patients' disadvantage. But if we have some figure, such as 10 per cent., to aim at it may help us at times to resist man's itch to achieve the impossible. During the last twelve months there have been 140 major operations for intracranial tumour on 125 patients, with fifteen deaths - an operation mortality of 10.7 per cent. and a case mortality of 12 per cent. (pituitary adenomas fifteen cases, no deaths ; congenital cysts ten, two deaths ; meningiomas eighteen, two deaths, twenty-four operations; tuberculomas four, no deaths; acoustics nine, two deaths from pneumonia; gliomas sixty-nine, nine deaths). One meningioma had four operations in a futile attempt to extirpate a large tumour straddling the wing of the sphenoid.

The tables give some idea of the perspective of neurosurgical work. The awakening of interest in the subject seems to ensure that it will increase rather than diminish, and most of us are hard put to get through our work. Neurosurgery has a reputation for long and arduous sittings ; but one has to make a choice, and I have made mine. The spectacular operator went out of fashion with the invention of anaesthesia, and in his place have come men of a less dramatic school. There is such a thing as style in operating: some people look better, others worse, than they really are. We all know the apparently poor technician who gets such good results, and feel that something is wrong there. But we remember that more important than what the surgeon does with his hands is the quality of mind which he brings to his task.

\section{AN UNUSUAL CASE OF LEAD POISONING}

$$
\text { BY }
$$

\section{G. E. BEAUMONT, D.M., F.R.C.P. Physician to Middlesex Hospital}

AND

\section{R. WYBURN-MASON, M.B., B.Chir. \\ Late House-physician to Middlesex Hospital}

This case presented the unusual combination of fever, severe abdominal pain, vomiting, jaundice, and epileptiform fits associated with temporary blindness.

\section{Clinical Record}

Previous Illnesses. - The patient, a railway signal clerk aged 16 , living at Crawley, Sussex, had a history of frequent attacks of abdominal pain, vomiting, and jaundice since childhood, resembling the present one but not so severe. For this reason his appendix had been removed four years previously, without benefit. In 1927 he had pneumonia, followed by empyema with rib resection. No previous history of fits was obtained.

Family History.-There was no family history of epilepsy. His elder brother had suffered from one attack of jaundice, and his sister had had a mild attack similar to our patient's about three years previously, since when she had not lived in the same cottage.

Present Illness.-On May 28, 1938, he collapsed while going to work, with general malaise, sleepiness, and severe central abdominal pain. His doctor found nothing abnormal except slight icterus and a temperature of $101^{\circ} \mathrm{F}$. The patient remained in much the same condition for a week, with a temperature ranging from $99.2^{\circ}$ to $100^{\circ} \mathrm{F}$. He then gradually improved and the temperature fell to normal in about eighteen days from the onset, when he was allowed to get up. He vas constipated throughout the illness, and his appetite was very 
poor. A blood count on June 30 showed: red cells, 3,400,000 per c.mm.; haemoglobin, 58 per cent.; colour index, 0.8 ; white cells, 4,700 per c.mm. On July 11 the patient was again seized with violent colicky abdominal pain. He vomited bile, was irritable, complained of a feeling of heaviness and weakness in the legs, and began to lose his sense of direction. $\mathrm{He}$ was very constipated, and again was slightly jaundiced. His motions were normal in colour. He became drowsy and difficult to rouse, and on July 15 he had three epileptiform fits at intervals of approximately two hours. These were followed by a severe headache, and he rapidly became blind He was admitted to the Middlesex Hospital that evening under our care, and had four more fits that night in a period of six hours.

Examination on Admission.-The patient was pale, the skin of a greyish hue, and the conjunctivae slightly icteric. Cerebration was slow and he was difficult to rouse. The pulse was regular, 100 ; temperature, $99.6^{\circ} \mathrm{F}$.; respiration, 16 and Cheyne-Stokes in character. The blood pressure was $145 / 122$ $\mathrm{mm}$. $\mathrm{Hg}$. The teeth were very good, and no blue line was seen on the gums or cheeks. The pupils were widely dilated, but reacted fairly briskly to light and accommodation. The fundi were normal; no papilloedema was present. Vision was limited to light perception only. The knee-jerks and anklejerks were brisk; the left plantar response was extensor and the right one was not obtained. (The patient had had a fit a short while previously.) The left upper abdominal reflex was absent. The specific gravity of the urine was 1020. Bile pigments were present, but there were no bile salts, albumin or sugar. While being examined the patient had an epileptiform attack, which began by his head and eyes turning to the right; his left "hand then moved to his face and became rigid. He said, "The attack is coming on." His eyes and head now turned to the left, the arms crossed over the chest, and the whole body went first into tonic and then into clonic spasms. The pupils were dilated and inactive to light. The clonic stage passed off suddenly after about two minutes; the patient micturated, and remained unconscious for about ten minutes. Three more fits occurred during the night, all of the same character.

Course of the Illness.-July 16, 1938: The temperature was $97^{\circ} \mathrm{F}$. in the morning, $98^{\circ}$ at 6 p.m., and $101.4^{\circ}$ at 10 p.m. There was no fit after the one at 2 a.m. Vision was still limited to light perception. Reflexes were now normal, except that the left plantar response was absent. Lumbar puncture showed the fluid under increased pressure of $270 \mathrm{~mm}$. $\mathrm{H}_{2} \mathrm{O}$. This was lowered to $150 \mathrm{~mm}$. by running off some fluid. Examination of the fluid showed 0.03 gramme of protein per cent. and 7 lymphocytes per c.mm. The Lange curve was normal and the Wassermann reaction negative. An enema gave a dark constipated result. Urine (twenty-four hours volume), $22 \mathrm{oz}$.

July 17: The temperature was now normal, and remained so. No more fits occurred. Blood pressure, $130 / 105 \mathrm{~mm}$. $\mathrm{Hg}$. Urine (twenty-four hours' volume), only $14 \mathrm{oz}$. The urine was sent for analysis for lead.

July 18: Much improved. No vomiting, no abdominal pain, and sight returning. He could now recognize faces. Urine (twenty-four hours' volume), $13 \mathrm{oz}$. Blood pressure, $115 / 85 \mathrm{~mm}$. Hg. The bowels were opened naturally. Lumbar puncture showed a clear fluid, with a pressure of $180 \mathrm{~mm}$. $\mathrm{H}_{2} \mathrm{O}$. This was reduced to $150 \mathrm{~mm}$. by drawing off cerebrospinal fluid.

July 19: Condition improving. Urine (twenty-four hours' volume), $38 \mathrm{oz}$.

July 20: The sight was now nearly normal. A sudden diuresis began and continued for six days; this period coincided with a fall of the blood nitrogen to normal (see investigations below). Urine (twenty-four hours' volume), $89 \mathrm{oz}$.

July 21: Urine (24 hours' volume), $93 \mathrm{oz}$. July 22: The patient was allowed up; urine ( 24 hours' volume), 73 oz.; blood pressure, $115 / 75 \mathrm{~mm}$. Hg. July 23 : Urine (24 hours' volume), $53 \mathrm{oz}$. July 24 : Urine ( 24 hours' volume), $77 \mathrm{oz}$. July 25: Urine ( 24 hours' volume), 62 oz. July 26: The patient felt quite normal; the icterus had disappeared: urine (24 hours' volume), $62 \mathrm{oz}$.

On September 4 the patient was discharged to a convalescent home, having gained $10 \mathrm{lb}$. in weight since admission and being free from all symptoms.

\section{Special Investigations}

The urine on July 16 contained a few hyaline casts, and red and white cells were present. There were no tyrosine or leucine crystals. On July 17 lead was found to the extent of 1 part in $10,000,000$ parts of urine. This is considered diagnostic of lead poisoning.

\section{THE BLOOD}

On July 16 a blood examination showed: red cells, 4,700,000 per c.mm.; haemoglobin, 92 per cent. ; colour index, 1; white cells, 11,000 per c.mm.-neutrophils 73 per cent., lymphocytes 19 per cent., monocytes 8 per cent. Three stippled cells per 100 leucocytes were present. This blood count suggested the diagnosis of lead poisoning. On August 5 the count gave: red cells, 4,800,000 per c.mm.; haemoglobin, 95 per cent. white cells, 9,100 . No stippling was seen.

Fragility of Red Cells.-The curve showed decreased fragility.

Van den Bergh Reactions.-July 16: Direct biphasic, positive ; indirect, positive ; quantitative $=7$ units bilirubin. August 5: Direct delayed, faintly positive ; indirect, faintly positive ; quantitative $=1$ unit bilirubin. September 1: Direct delayed and indirect, negative: quantitative $=$ less than 0.5 unit bilirubin.

Wassermann Reaction.-Negative.

Alkali Reserve.-July 16: 61 c.cm. $\mathrm{CO}_{2}$ per cent.

Blood Urea and Non-protein Nitrogen

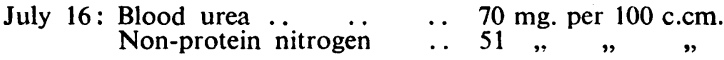

$$
\begin{aligned}
& \text { July 21: Blood urea . } \\
& \text { Non-protein nitrogen } \\
& \text { July 27: Blood urea } \\
& \text { Non-protein nitrogen }
\end{aligned}
$$

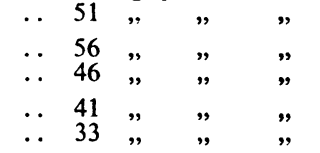

There was no evidence of lead in the limb bones. Radiographs of the chest, head, and abdomen were normal.

\section{Results of the Investigations}

The conclusions drawn from the investigations were that: (a) lead poisoning was present, as shown by the stippling of the red cells and the lead in the urine; $(b)$ the temporary retention of nitrogen in the blood coincided with the period of oliguria and disappeared with diuresis ; (c) there was no evidence of nephritis; $(d)$ the temporary excess of bilirubin in the blood was due probably to haemolysis, which would account for the slight icterus; (e) increased intracranial pressure was present, but there was no evidence of meningitis; $(f)$ the decreased fragility of the red cells is the opposite to what occurs in acholuric jaundice ; and $(g)$ the anaemia was temporary.

When lead poisoning was diagnosed as the result of the clinical findings, blood film, and urine analysis difficulty was experienced in tracing the source of the poison. There was no history of occupational risk other than the presence of lead storage batteries under the signal-box where the patient worked. Further, he had worked there for a short time only. Inquiry into the water supply of the patient's home elicited the fact that the water was obtained from a well by pumping through lead pipes. The first sample of water analysed showed no trace of lead. It was then found that this had been obtained after a free pumping. Analysis of a second sample, obtained after allowing the water to stand in the pipes, showed 4 parts of lead in $10,000,000$ parts of water. 


\section{Treatment}

The patient was first treated with milk, four pints in the twenty-four hours, glucose, and calcium lactate 30 grains thrice daily, with the idea. of removing the lead from the circulation to the bones. After the acute symptoms had subsided an attempt at "deleading" was begun on August 6 by means of a low calcium diet and the intramuscular injection of 50 units of parathormone daily. The urine collected from August 6 to 8, however, contained no lead.

\section{Discussion}

The clinical diagnosis was obscure for certain reasons:

1. Suggested Intestinal Infection.-The febrile illness of eighteen days' duration with abdominal symptoms and slight jaundice suggested some intestinal infection. The temperature in the toxic crises of lead poisoning rarely rises $1^{\circ} \mathrm{F}$. above normal (Aub et al., 1926). The pyrexia could not be due to the fits, as no fits had occurred for more than twenty hours before the sudden rise to $101.4^{\circ} \mathrm{F}$. cn July 16. Thus it appears that the temperature was due to an intercurrent infection. Further, latent cases of lead poisoning may be unmasked by intercurrent infection (Shie, 1921). It is therefore possible that the exciting cause of the toxic episodes in this case of chronic lead poisoning was an infection. The previous similar attacks, for which the appendix was removed, were probably toxic episodes of lead poisoning also.

2. Possibility of Uraemia.-The oliguria and raised blood nitrogen suggested the possibility of uraemia, accounting for the fits and amaurosis; such attacks are, however, usually considered to be due to hypertensive encephalopathy, and the blood pressure was not high enough in this case to cause vascular spasm. The urine did not suggest evidence of renal damage, as there was no albumin, and only a few hyaline casts were found. Furthermore, as the urine output increased the blood nitrogen fell to normal. It therefore appears probable that the increased blood nitrogen and the oliguria were due to the effects of the lead, causing vascular spasm and dimınishing the blood supply through the kidneys. There was no evidence of uraemia. Oliguria with a rise of blood nitrogen during the abdominal crises of lead poisoning followed by a diuresis and fall in the blood urea has been described by Achard and Leblanc (1914) and Mosny and Javal (1914). These changes cannot be due to renal arteriosclerosis, since they occur even after a short exposure to lead; nor can they result from nephritis, because the urine contains no albumin and no casts. Moreover, the patients do not subsequently develop renal lesions if the exposure to lead ceases. Continued exposure to lead is liable to result in chronic nephritis, possibly owing to prolonged vascular spasm. There is no evidence that the raised blood urea is due to excessive tissue breakdown, as there is no wasting, loss of weight, or pyrexia, and this would not explain the oliguria. Mosny and Javal (1914) compare the condition in lead poisoning with that of calculous anuria, in which there is an enormous azotaemia which disappears when the cbstruction is removed, and they suggest that there is a reflex inhibition of the kidney function. This inhibition in lead poisoning we suggest is due to vascular spasm, resulting in oliguria and failure of elimination of nitrogenous products in the urine.

3. Fits.-These are manifestations of lead encephalopathy. This has been attributed (Aub et al., 1926) to various causes, such as: (a) Cerebral Arteritis and Arteriosclerosis.-These lesions have not been demonstrated at necropsy.

(b) Punctate Cerebral Haemorrhages. - These also have not been found post mortem.

(c) Direct Action of Lead on the Cortical Cells of the Brain.-Lead is present in small amounts in the brain, but no macroscopic or microscopical changes are seen, except some evidence of anaemia in the grey matter.

(d) A Meningeal Lesion.-The pressure of the cerebrospinal fluid is often raised, as in our case. Hassin (1921) states that at necropsy proliferative meningitis with some round-celled infiltration is present, but the brain changes are slight. Experimental injection of lead salts into the cerebrospinal fluid causes excitement and convulsions in dogs, but if the injection is made direct into the brain the only lesion found is a slow necrosis of the surrounding brain tissue. Intravenous injection is said not to cause encephalopathy. Mosny and Malloizel (1907) and others record an increase in the lymphocyte content of the cerebrospinal fluid in lead encephalopathy up to 100 lymphocytes per c.mm. The normal protein content of the cerebrospinal fluid and the very slight increase in the cell count in our case suggest that meningitis was not present. The increase in the pressure of the cerebrospinal fluid might be secondary to cerebral spasm followed by oedema.

(e) Uraemia.-This theory implies the occurrence of hypertensive encephalopathy, and has been discussed above and discarded.

(f) Cerebral Anaemia.-This appears to be the most likely cause. Arterioles placed in solutions of lead salts contract (Siccardi and Dozzi, 1914). Aub et al. (1926) state that vascular spasm leading to cerebral anaemia cannot be the cause of the fits, since there is no general rise in the blood pressure. In our case there was a slight but definite rise, which, combined with the local action of the lead on the capillaries, would possibly be sufficient to cause vascular spasm, cerebral anaemia, and oedema. This would explain the focal nature of the epileptiform discharges and also the raised cerebrospinal fluid pressure.

4. The Amaurosis.-Visual disturbances are well recognized in lead poisoning, especially optic neuritis, optic atrophy, retrobulbar neuritis, and hemianopia. The acute onset of blindness, with an equally rapid disappearance, suggests that no organic lesion could be present in the fundus or optic nerve connexions. The amaurosis might be due to retrobulbar neuritis, but the blotting out of the peripheral and central fields of vision, the response of the pupils to light and accommodation, and the rapid restoration of vision suggest that the lesion was situated in the visual area of the occipital cortex. It could be explained by local spasm of the vessels with some associated oedema, due to the action of lead on the vessels and associated with some rise of the blood pressure, which fell again as sight was recovered.

\section{Conclusions}

The encephalopathy, transient blindness, oliguria, and raised blood urea associated with abdominal pain can all be explained by the action of lead on plain muscle, causing it to contract. The anaemia and slight jaundice result from haemolysis.

\section{Summary}

The clinical record of an unusual case of lead poisoning is presented, with an account of the investigations made.

The results of these investigations are given, together with the conclusions drawn from them.

The reasons for the obscurity of the clinical diagnosis are discussed.

Dr. Sidney Matthews, who arranged for the admission of the case to Middlesex Hospital, kindly supplied us with the 
details of the patient's family history and his condition before arrival in hospital and with specimens of water for analysis. $\mathrm{He}$ told us that the water came from a well, from which it was carried to the sink by a lead pipe. We wish to express our thanks to the special departments of the hospital for help in the investigations.

\section{REFERENCES}

Achard, C., and Leblanc, A. (1914). Bull. Mém. Soc. méd. Hôp. Paris, 3 ser. 37,701 .

Aub, J. C., Fairhall, L. T., Minot, A. S., and Reznikoff, P. (1926). Lead Poisoning. Med. Monographs, vol. 7, Baltimore.

Hassin, G. B. (1921). Arch. Neurol. Psychiat., Chicago, 6, 268.

Mosny and Javal (1914). Bull. Mém. Soc. méd. Hôp. Paris, 3 ser., 37, 869 .

and Malloizel (1907). Rev. Médecine, 27, 505.

Shie, M. D. (1921). J. Amer. med. Ass. 76, 835.

Siccardi, P. D., and Dozzi, L. (1914). Clin. med. ital., 53, 3.

\section{A PLEA FOR THE FREER USE OF BLOOD TRANSFUSION IN OBSTETRICS}

BY

\section{JOHN STALLWORTHY, M.B., Ch.B., F.R.C.S., M.C.O.G.}

First Assistant, Nuffield Department of Obstetrics and Gynaecology, University of Oxford

One woman dies every day in England and Wales from haemorrhage in childbirth. This statement is based on figures supplied by the Registrar-General, and takes no account of those deaths from sepsis in which anaemia is a contributing factor. When the frequent morbidity due to post-abortal and puerperal anaemia is remembered, the importance of haemorrhage in pregnancy is still more striking. The annual death roll from this cause in America has been assessed at 1,500 and in Germany at 400. There is a tendency to believe that deaths from haemorrhage occur in those parts of the country in which obstetrical and surgical facilities are not so readily available as in most of the large centres, but an evening spent in reading the annual reports of obstetrical hospitals will convince any reader that this is not correct. He will be surprised by the number of deaths occurring directly from haemorrhage, and still more will he be surprised to find how seldom an attempt was made in these cases to restore the blood loss even in circumstances which might be considered ideal from the point of view of treatment and facilities.

Although so many articles have been published in recent years on the subject of blood transfusion its importance is still not fully realized. Public opinion would be shocked if 100 passengers on a liner were drowned simply because lifeboats available were not used; but when, in England and Wales alone, over three times this number of women die annually from obstetrical haemorrhage there is a tendency to regard the loss as inevitable, and insufficient vigour is displayed in organizing the facilities available that these deaths may be prevented.

It is not within the scope of this paper to discuss the great importance of prophylaxis in obstetrical haemorrhage. It is fitting, however, to draw attention to the fact that many of the most severe haemorrhages are preceded by some significant warning. Thus, preliminary small losses often announce the presence of a placenta praevia, and it is courting disaster in such cases to wait for a severe haemorrhage before grouping the patient and arranging for compatible donors. The case in which there is doubt as to the advisability of a transfusion is not under discussion. The value of saline, glucose saline, or gum infusion has been stressed on many occasions, but when blood loss has been extreme it is well to remember that the effect of these remedies is fleeting and that lasting benefit comes only from replacement of blood. The exsanguinated patient may revive after saline infusion, but, as already indicated, the annual death roll is increased by the many who do not. These are the cases I now wish to discuss.

Solomons (1938) in an article on tubal pregnancy made the following arresting statement:

"Blood transfusion was not employed for any patient. ... Patients have been killed by venous transfusion in this condition and in others, and at this stage I should like to utter a warning against indiscriminate blood transfusions and to emphasize the value of submammary and rectal saline, glucose, and coffee. The ambulatory intravenous services suggested in England and in other places have done and will do harm, even though they will be occasionally useful."

In spite of the excellent results Solomons reported in his series of 214 cases without a death, his words cannot be allowed to pass unchallenged. To discuss fairly the dangers of blood transfusion it would be necessary to consider the pathology of those conditions for which it has been advocated and used. Such a discussion would also embrace the question of age, blood volume, and other factors which are not relevant to this paper. It is sufficient to state that transfusion in cases of severe blood loss due to acute haemorrhage during the age period with which this paper is necessarily concerned is justified by theory and its value established by practice. In an extensive experience of such transfusions I have seen no disasters.

\section{Fatal Cases following Blood Loss}

Those who subscribe to the views stated by Solomons must find it difficult to explain the many cases recorded annually in hospital reports in such words as the following:

"She was admitted to hospital at 12.10 a.m. on May 17 with a retained placenta. She was in an extremeiy shocked condition and had had a very severe intra-partum haemorrhage before admission. On admission she was still bleeding profusely. A light anaesthetic was given and the placenta manually removed. An intravenous gum saline was then given, but the patient never rallied, and she died soon afterwards."

"Immediately following the delivery of the placenta brisk post-partum haemorrhage occurred, which responded well to ergometrine intramuscularly and hot intra-uterine douching. Following this the patient's general condition was poor, her blood pressure was $80 / 56$, and her pulse almost imperceptible at the wrist. However, after the administration of $100 \mathrm{c.cm}$. of 50 per cent. glucose solution intravenously and morphia grain $\frac{1}{4}$, raising the bed, and bandaging the limbs, her condition improved remarkably and remained satisfactory for three hours, when she suddenly collapsed and died."

"The patient was delivered spontaneously of a living child which had presented by the breech, and satisfactory analgesia was obtained with the Minnitt apparatus. A severe post-partum haemorrhage followed, and manual removal of the placenta was performed under general anaesthesia. In spite of treatment she died from haemorrhage two hours later."

These examples from three recent separate reports might be multiplied many times.

All who have had experience of the effects of transfusion on patients who are exsanguinated will testify to the dramatic improvement it produces in most cases. One may ask why; if this is true, transfusion is not used more often in emergency cases. The answer is that in hospitals resident medical officers are frequently not "transfusion minded" and regard the giving of blood as a difficult and laborious procedure. For this attitude of mind the respon- 